\title{
COMMENTARY
}

\section{Estimation of dead space fraction can be simplified in the acute respiratory distress syndrome}

\author{
Davide Chiumello*1 and Elisabetta Gallazzi² \\ See related research by Siddiki et al., http://ccforum.com/content/14/4/R141
}

\begin{abstract}
Acute lung injury and acute respiratory distress syndrome are characterized by a non-cardiogenic pulmonary edema responsible for a significant impairment of gas exchange. The pulmonary dead space increase, which is due primarily to an alteration in pulmonary blood flow distribution, is largely responsible for carbon dioxide retention. Previous studies, computing the pulmonary dead space by measuring the expired carbon dioxide and the Enghoff equation, found that the dead space fraction was significantly higher in the non-survivors; it was even an independent risk of death. The computation of the dead space not by measuring the expired carbon dioxide but by applying a rearranged alveolar gas equation that takes into account only the weight, age, height, and temperature of the patient could lead to widespread clinical diffusion of this measurement at the bedside.
\end{abstract}

In the previous issue of Critical Care, Siddiki and colleagues [1] presented the dead space fraction data collected at admission and on day 3 from two acute lung injury/acute respiratory distress syndrome (ALI/ARDS) databases (109 patients in the Mayo Clinic and 1,896 patients in the ARDS Network). The hospital mortality increased in direct proportion to an increase in the dead space fraction. For every 0.05 increment of the dead space fraction, the odds ratios for hospital mortality were 1.07 at day 1 and 1.12 at day 3. Thus, at first sight, the results of Siddiki and colleagues represent merely a repetition of previous studies [2-4]. However, their study added a novel element in that the dead space fraction was computed more simply than in the previous studies [2-4]

\footnotetext{
*Correspondence: chiumello@libero.it

'Dipartimento di Anestesia, Rianimazione e Terapia del dolore, Fondazione IRCCS, Cà Granda - Ospedale Maggiore Policlinico, Via F. Sforza 35, Milan, Italy

Full list of author information is available at the end of the article
}

and, unlike in those studies, without monitoring of the expired carbon dioxide $\left(\mathrm{CO}_{2}\right)$. So that the current results may be better understood, a short summary of the theoretical aspects of the dead space computation is presented.

ALI and ARDS are characterized by a non-cardiogenic pulmonary edema with significant impairment of gas exchange. The increases in the right-to-left intrapulmonary shunt and in low ventilation-to-perfusion ratio lead to hypoxemia, whereas the increase in pulmonary dead space reduces $\mathrm{CO}_{2}$ removal $[5,6]$. The increase in pulmonary dead space is due mainly to alterations in the distribution of pulmonary blood flow originating from vascular obstruction and to regional overdistension of ventilated alveoli induced by the application of positive end-expiratory pressure (PEEP) and sometimes by the reduction in cardiac output [7-9].

Nuckton and colleagues [10] found that in patients with ARDS the pulmonary dead fraction measured at admission was significantly higher in the non-survivors than in the survivors $(0.63 \pm 0.09$ versus $0.54 \pm 0.09)$; for every increase of 0.05 in the dead space fraction, the odds ratio of death increased by $45 \%$. Subsequent studies showed that the dead space fraction, measured during the first 6 days of mechanical ventilation, was significantly higher in the non-survivors than in the survivors and in patients with ARDS compared with patients with ALI [2-4]. The odds ratios of death were 1.59 and 2.87 in the early and intermediate phases of ARDS, respectively [4].

The original Bohr's equation required the mean alveolar $\left(\mathrm{PA}_{\mathrm{CO} 2}\right)$ and mixed expired $\left(\mathrm{PE}_{\mathrm{CO} 2}\right)$ partial pressures of $\mathrm{CO}_{2}$ in order to estimate the physiologic dead space: $\left(\mathrm{PA}_{\mathrm{CO} 2}-\right.$ $\mathrm{PE}_{\mathrm{CO} 2} / \mathrm{PA}_{\mathrm{CO} 2}$. Subsequently, given the difficulty of measuring the $\mathrm{PA}_{\mathrm{CO} 2}$ and given that $\mathrm{PA}_{\mathrm{CO} 2}$ and arterial pressure of $\mathrm{CO}_{2}\left(\mathrm{~Pa}_{\mathrm{CO} 2}\right)$ are nearly identical in normal subjects, Enghoff suggested that $\mathrm{Pa}_{\mathrm{CO} 2}$ be used instead of $\mathrm{PA}_{\mathrm{CO}} ;$ consequently, the new equation was $\mathrm{Pa}_{\mathrm{CO} 2}-$ $\mathrm{PE}_{\mathrm{CO} 2} / \mathrm{Pa}_{\mathrm{CO} 2}$. Thus, any changes in intrapulmonary shunting, ventilation/perfusion ratio, or $\mathrm{CO}_{2}$ solubility (Haldane effect) can affect the pulmonary dead space.

Traditionally, the $\mathrm{PE}_{\mathrm{CO} 2}$ has been measured over several minutes by collecting the expired gas (into a Douglas 
bag) and analyzing it with a blood gas analyzer [11]. Nowadays, indirect calorimeters or volumetric capnography allows accurate $\mathrm{PE}_{\mathrm{CO} 2}$ measurements at the bedside [11-13]. Unfortunately, these methods can be cumbersome and thus may limit the widespread measurement of dead space in clinical practice.

In the present study, Siddiki and colleagues [1] 'estimated' the physiologic dead space not by taking into account the $\mathrm{PE}_{\mathrm{CO} 2}$ but by applying a rearranged alveolar gas equation. The dead space was equal to $1-[(0.86 \times$ $\dot{\mathrm{V}}_{\mathrm{CO} 2}$ estimated)/(minute ventilation $\left.\times \mathrm{Pa}_{\mathrm{CO} 2}\right]$. The $\dot{\mathrm{V}}_{\mathrm{CO} 2}$ estimated (the estimated $\mathrm{CO}_{2}$ production) is simply measured by the Harris-Benedict equation, which takes into consideration the weight, height, age, and body temperature of the patient. The Harris-Benedict equation is commonly used to predict the resting energy expenditure (REE) [14].

There are some important limitations to the study by Siddiki and colleagues: (a) the absence of any comparison of the physiologic dead space measurements obtained with the rearranged alveolar gas equation and with the Enghoff equation and (b) the use of the Harris-Benedict equation, which has been reported to be weakly related to the REE in severely ill patients [15]. However, even with these limitations, these data suggest that the pulmonary dead space can be measured in ALI/ARDS patients non-invasively, rapidly, and without any expensive equipment. Thus, in addition to taking daily measurements of oxygenation, compliance, and transpulmonary pressure, clinicians should include the pulmonary dead space for better clinical management.

\section{Abbreviations}

$\mathrm{ALI}$, acute lung injury; ARDS, acute respiratory distress syndrome; $\mathrm{CO}_{2}$, carbon dioxide; $\mathrm{Pa}_{\mathrm{Coz}}$ arterial partial pressure of carbon dioxide; $\mathrm{PA}_{\mathrm{cor}}$ alveolar partial pressure of carbon dioxide; $\mathrm{PE}_{\mathrm{CO} 2}$ expired partial pressure of carbon dioxide; $\mathrm{REE}$, resting energy expenditure; $\mathrm{V}_{\mathrm{C}_{2}}$ estimated, estimated carbon dioxide production.

\section{Competing interests}

The authors declare that they have no competing interests.

\section{Author details}

'Dipartimento di Anestesia, Rianimazione e Terapia del dolore, Fondazione IRCCS, Cà Granda - Ospedale Maggiore Policlinico, Via F. Sforza 35, Milan, Italy. 2Dipartimento di Anestesiologia, Terapia Intensiva e Scienze Dermatologiche, Università degli Studi di Milano, Via Festa del Perdono 7, 20122 Milan, Italy.

Published: 9 September 2010
References

1. Siddiki H, Kojicic M, Li G, Yilmaz M, Thompson TB, Hubmayr RD, Gajic O: Bedside quantification of dead-space fraction using routine clinical data in patients with acute lung injury: secondary analysis of two prospective trials. Crit Care 2010, 14:R141.

2. Kallet RH, Alonso JA, Pittet JF, Matthay MA: Prognostic value of the pulmonary dead-space fraction during the first 6 days of acute respiratory distress syndrome. Respir Care 2004, 49:1008-1014.

3. Lucangelo U, Bernabe F, Vatua S, Degrassi G, Villagra A, Fernandez R, Romero PV, Saura P, Borelli M, Blanch L: Prognostic value of different dead space indices in mechanically ventilated patients with acute lung injury and ARDS. Chest 2008, 133:62-71.

4. Raurich JM, Vilar M, Colomar A, Ibáñez J, Ayestarán I, Pérez-Bárcena J, Llompart-Pou JA: Prognostic value of the pulmonary dead-space fraction during the early and intermediate phases of acute respiratory distress syndrome. Respir Care 2010, 55:282-287.

5. Dantzker DR, Brook CJ, Dehart P, Lynch JP, Weg JG: Ventilation-perfusion distributions in the adult respiratory distress syndrome. Am Rev Respir Dis 1979, 120:1039-1052.

6. Ralph DD, Robertson HT, Weaver LJ, Hlastala MP, Carrico CJ, Hudson LD: Distribution of ventilation and perfusion during positive end-expiratory pressure in the adult respiratory distress syndrome. Am Rev Respir Dis 1985 131:54-60.

7. Coffey RL, Albert RK, Robertson HT: Mechanisms of physiological dead space response to PEEP after acute oleic acid lung injury. J App/ Physiol 1983, 55:1550-1557.

8. Suwa K, Hedley-Whyte J, Bendixen HH: Circulation and physiologic dead space changes on controlling the ventilation of dogs. J App/ Physio/ 1966 21:1855-1859.

9. Tomashefski JF Jr., Davies P, Boggis C, Greene R, Zapol WM, Reid LM: The pulmonary vascular lesions of the adult respiratory distress syndrome. Am J Pathol 1983, 112:112-126.

10. Nuckton TJ, Alonso JA, Kallet RH, Daniel BM, Pittet JF, Eisner MD, Matthay MA Pulmonary dead-space fraction as a risk factor for death in the acute respiratory distress syndrome. N Engl J Med 2002, 346:1281-1286.

11. Lum L, Saville A, Venkataraman ST: Accuracy of physiologic deadspace measurement in intubated pediatric patients using a metabolic monitor: comparison with the Douglas bag method. Crit Care Med 1998, 26:760-764

12. Kallet RH, Daniel BM, Garcia O, Matthay MA: Accuracy of physiologic dead space measurements in patients with acute respiratory distress syndrome using volumetric capnography: comparison with the metabolic monitor method. Respir Care 2005, 50:462-467.

13. MacKinnon JC, Houston PL, McGuire GP: Validation of the Deltatrac Metabolic Cart for measurement of dead-space-to-tidal-volume ratio. Respir Care 1997, 42:761-764.

14. Harris J, Benedict F: A Biometric Study of Basal Metabolism in Man (Publication No. 279). Washington, DC: Canergie Institute of Washington; 1919.

15. Carlsson M, Nordenstrom J, Hedenstierna G: Clinical implications of continuous measurement of energy expenditure in mechanically ventilated patients. Clin Nutr 1984, 3:103-110.

doi:10.1186/cc9237

Cite this article as: Chiumello D, Gallazzi E: Estimation of dead space fraction can be simplified in the acute respiratory distress syndrome. Critical Care 2010, 14:195. 